\title{
Solid Lymph Nodes as an Imaging Biomarker for Risk Stratification in Human Papillomavirus-Related Oropharyngeal Squamous Cell Carcinoma
}

\author{
(D)T.J. Rath, DS. Narayanan, (DM.A. Hughes, DR.L. Ferris, DS.I. Chiosea, and (DB.F. Branstetter IV
}

\begin{abstract}
BACKGROUND AND PURPOSE: Human papillomavirus-related oropharyngeal squamous cell carcinoma is associated with cystic lymph nodes on CT and has a favorable prognosis. A subset of patients with aggressive disease experience treatment failure. Our aim was to determine whether the extent of cystic lymph node burden on staging CT can serve as an imaging biomarker to predict treatment failure in human papillomavirus-related oropharyngeal squamous cell carcinoma.
\end{abstract}

MATERIALS AND METHODS: We identified patients with human papilloma virus-related oropharyngeal squamous cell carcinoma and staging neck CTs. Demographic and clinical variables were recorded. We retrospectively classified the metastatic lymph node burden on $\mathrm{CT}$ as cystic or solid and assessed radiologic extracapsular spread. Biopsy, subsequent imaging, or clinical follow-up was the reference standard for treatment failure. The primary end point was disease-free survival. Cox proportional hazard regression analyses of clinical, demographic, and anatomic variables for treatment failure were performed.

RESULTS: One hundred eighty-three patients were included with a mean follow-up of 38 months. In univariate analysis, the following variables had a statistically significant association with treatment failure: solid-versus-cystic lymph nodes, clinical T-stage, clinical N-stage, and radiologic evidence of extracapsular spread. The multivariate Cox proportional hazard model resulted in a model that included solid-versus-cystic lymph nodes, T-stage, and radiologic evidence of extracapsular spread as independent predictors of treatment failure. Patients with cystic nodal metastasis at staging had significantly better disease-free survival than patients with solid lymph nodes.

CONCLUSIONS: In human papilloma virus-related oropharyngeal squamous cell carcinoma, patients with solid lymph node metastases are at higher risk for treatment failure with worse disease-free survival. Solid lymph nodes may serve as an imaging biomarker to tailor individual treatment regimens.

ABBREVIATIONS: HPV = human papilloma virus; $\mathrm{OPSCC}=$ oropharyngeal squamous cell carcinoma; $r E C S=$ radiologic evidence of extracapsular spread; $\mathrm{TF}=$ treatment failure; TNM $=$ Tumor, Node, Metastasis

$\mathbf{H}^{\mathrm{n}}$ uman papillomavirus (HPV)-related oropharyngeal squamous cell carcinoma (OPSCC) is a distinct disease with more favorable locoregional control and survival outcomes compared with HPV-unrelated OPSCC. ${ }^{1-3}$ The favorable prognosis of

Received October 18, 2016; accepted after revision February 7, 2017.

From the Departments of Radiology (T.J.R., M.A.H., B.F.B.), Otolaryngology (T.J.R., M.A.H., R.L.F., B.F.B.), and Pathology (S.I.C.), University of Pittsburgh Medical Center, Pittsburgh, Pennsylvania; and Department of Radiology (S.N.), Children's Hospital of Pittsburgh of the University of Pittsburgh Medical Center, Pittsburgh, Pennsylvania.

Paper previously presented at: Annual Meeting of the American Society of Neuroradiology and Foundation of the ASNR Symposium, May 17-22, 2014; Montreal, Quebec, Canada: Number O-390.

Please address correspondence to Tanya J. Rath, MD, Department of Radiology, 200 Lothrop St, 2nd Floor, Suite 200 East Wing, Pittsburgh, PA 15213; e-mail: rathtj@upmc.edu

http://dx.doi.org/10.3174/ajnr.A5177
HPV-related OPSCC has prompted research directed at developing de-escalation treatment protocols that would offer reduced toxicity to patients at low risk of treatment failure (TF). ${ }^{4}$ Furthermore, the current anatomic-based Tumor, Node, Metastasis (TNM) Staging System is not well-suited to predicting outcome in HPV-related OPSCC. ${ }^{5,6}$ Despite its favorable prognosis, a subset of HPV-related OPSCCs recur primarily with distant metastases and frequently in atypical locations. ${ }^{3,7-10}$ Imaging biomarkers that stratify patients at risk for TF would be useful to identify patients who are not candidates for de-escalation therapy. HPVrelated OPSCC is associated with cystic-appearing lymph nodes on CT, but some patients with HPV-associated disease have completely solid metastases. ${ }^{11,12}$ The purpose of this study was to determine whether solid and cystic lymph node metastases on staging neck CT could be used as an imaging biomarker to predict TF in patients with stage III or IV HPV-related OPSCC. 

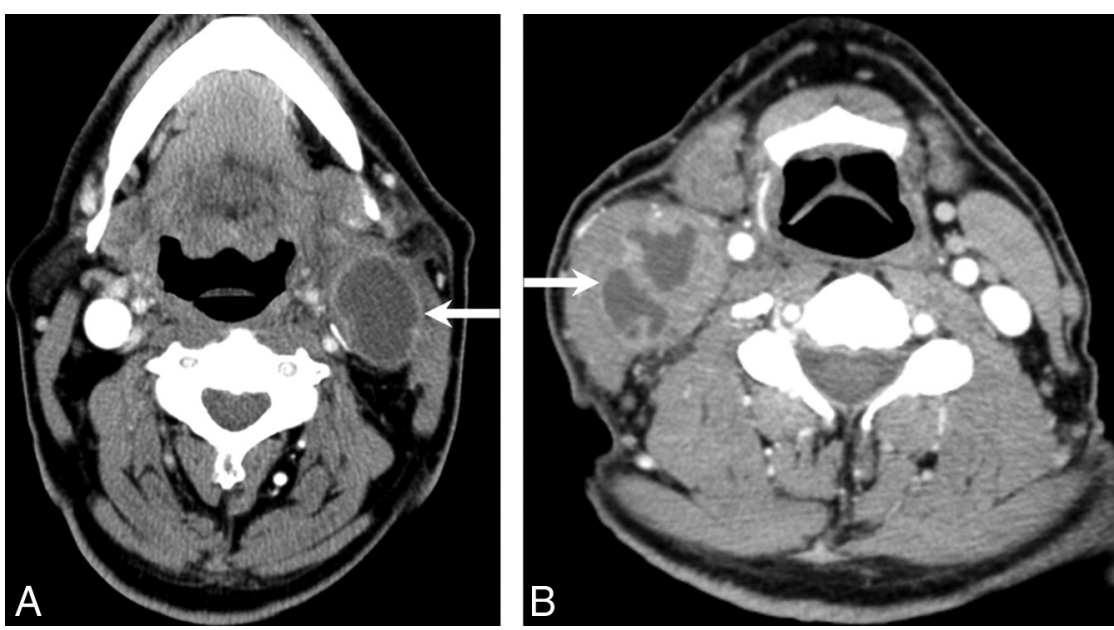

FIG 1. $A$ and $B$, Two examples of metastatic lymph nodes (white arrows) classified as cystic.

\section{MATERIALS AND METHODS Study Sample}

This retrospective Health Insurance Portability and Accountability Act-compliant single-institution study was approved by the institutional review board. Four hundred forty-one patients with HPV-positive OPSCC were identified from our head and neck cancer registry from 1984 to $2014 .{ }^{13,14} \mathrm{HPV}$ positivity was determined by in situ hybridization by using probes targeting $37 \mathrm{HPV}$ subtypes, including the following: 6, $11,16,18,31,33,35,39,45,51$, and 52 (Y1404; Dako, Carpinteria, California). Five-micrometer tissue sections were deparaffinized and digested with proteinase K (Roche Diagnostics, Indianapolis, Indiana). Cases with punctate nuclear signal were considered positive. ${ }^{14}$ Before 2007, HPV positivity was determined retrospectively on available tissue blocks by a head and neck cancer pathologist (S.I.C.) blinded to clinical outcome. ${ }^{14}$ Exclusion criteria were the following: unavailable contrast-enhanced staging CT $(n=221)$, N0 disease on staging CT or pathology $(n=21)$, no clinical follow-up $(n=10)$, noncompliance with the prescribed treatment regimen $(n=5)$, and distant metastases at presentation $(n=1)$. The reference standard for nodal metastasis at staging was histologic confirmation or definitively abnormal-appearing lymph nodes on staging CT in a patient with biopsy-proved HPV-positive OPSCC.

Patient demographics, TNM classification as defined by the seventh edition of the AJCC Cancer Staging Manual, primary tumor site, tobacco use, treatment, and status at last follow-up (alive/died and disease-free or TF) were collected from the head and neck cancer registry, medical records, and death registry. ${ }^{15}$ For this study, TF was defined to include persistent residual disease 3 months following completion of definitive therapy, locoregional recurrence following a disease-free period, development of distant metastasis, or disease-related mortality of the patient. The reference standard for TF was histologic confirmation or unequivocal imaging evidence of locoregional recurrence or distant metastasis. TF was documented from the time of initial diagnosis. In cases without TF, follow-up was measured in months from diagnosis. The data were censored to the last follow-up in the medical record through July 29, 2016.

\section{Neck CT Scans}

Staging contrast-enhanced neck CT or the diagnostic contrast-enhanced neck CT portion of a staging PET/CT was reviewed for all subjects. The technique was variable, with staging neck CTs performed on 8-, 16-, or 64-channel CT scanners (GE Healthcare, Milwaukee, Wisconsin). A typical staging neck CT scan performed on a 64-channel scanner (GE Healthcare) 80 seconds following the administration of IV contrast (100-mL iopamidol, Isovue-370; Bracco, Princeton, New Jersey) used the following parameters: voltage $=120 \mathrm{kV}$ (peak), tube current $=100-550 \mathrm{~mA}$ (automatic tube current modulation with a noise index of 9.1), pitch $=0.969 \mathrm{~mm} /$ rotation, gantry rotation time $=0.8$ seconds, detector collimation $=64 \times 0.625 \mathrm{~mm}$, FOV $=22 \mathrm{~cm}, 2.5 \mathrm{~mm}$ axial reconstructed section thickness with soft-tissue and bone algorithms. The neck CT for the diagnostic PET/CT examinations performed on 16- to 64-channel PET/CT scanners (Discovery; GE Healthcare) used the following parameters 30 seconds following the administration of IV contrast (125-mL iopamidol, Isovue-370): $120-30 \mathrm{kVp}$, variable $\mathrm{mA}$ (AutomA, GE Healthcare), 2.5-mm axial reconstructed section thickness through the neck, and 3.75-mm reconstructed section thickness through the body. All CT scans included in the study were deemed diagnostically adequate by both reviewing radiologists.

\section{Image Analysis}

Blinded consensus review of the CT scans was performed by 2 neuroradiologists (T.J.R. and B.F.B.). All morphologically abnormal lymph nodes in a patient were grouped together and classified as either cystic ( $>20 \%$ cystic change) or solid $(<20 \%$ cystic change) (Figs 1 and 2). Cystic change was defined as a homogeneous low-attenuation area relative to normal muscle that was subjectively near-water attenuation with well-defined margins. Radiologic extracapsular spread (rECS) in metastatic cervical lymph nodes was defined as irregular nodal margins with invasion or distortion of surrounding soft tissues, regardless of nodal size, cystic change, or the number of pathologic nodes (Fig 3).

\section{Treatment and Clinical Follow-Up}

All patients were treated and followed according to standard institutional practice guidelines by a multidisciplinary head and neck cancer team. Patients underwent head and neck clinical examination 2 months after the conclusion of therapy and every 3 months thereafter for the first 2 years as long as they were free of disease. Subsequent follow-up typically includes clinical evaluation every 3 months for the third year and every 6 months for the fourth and fifth years following completion of treatment. All patients had a minimum of 1 posttreatment contrast-enhanced PET/CT or contrast-enhanced soft-tissue neck CT and a chest CT, starting 2-3 months after completion of therapy, with serial imaging thereafter at the discretion of the clinical team. Patients with suspicious radiologic or clinical findings underwent biopsy for 

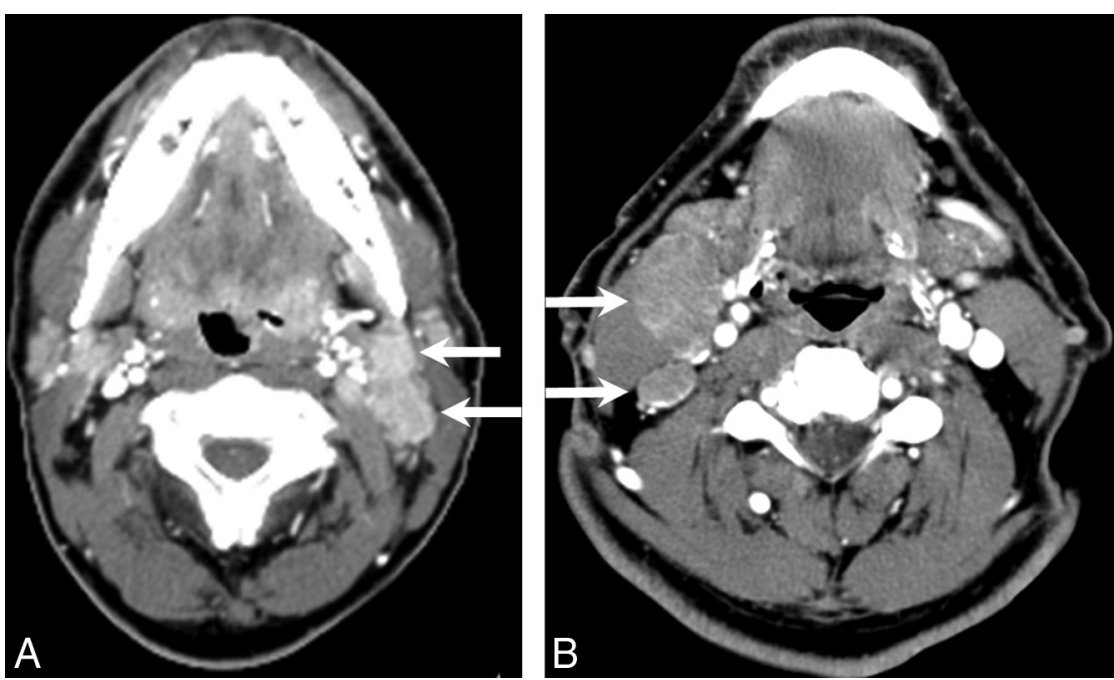

FIG 2. $A$ and $B$, Two examples of metastatic lymph nodes (white arrows) classified as solid. statistics. Kaplan-Meier survival curves were plotted to visually compare disease-free survival in patients with solid-versus-cystic lymph nodes.

\section{RESULTS}

Patient Characteristics

Of $441 \mathrm{HPV}$-positive patients identified in the tumor registry from 1984 to 2014, 183 patients met the inclusion criteria (Fig 4). These 183 patients were treated between calendar years 2001 and 2014. Table 1 characterizes the patient demographics, tumor site, and staging information for all patients, categorized by solid and cystic patterns of nodal metastasis. There was no statistically significant correlation found among any of the listed

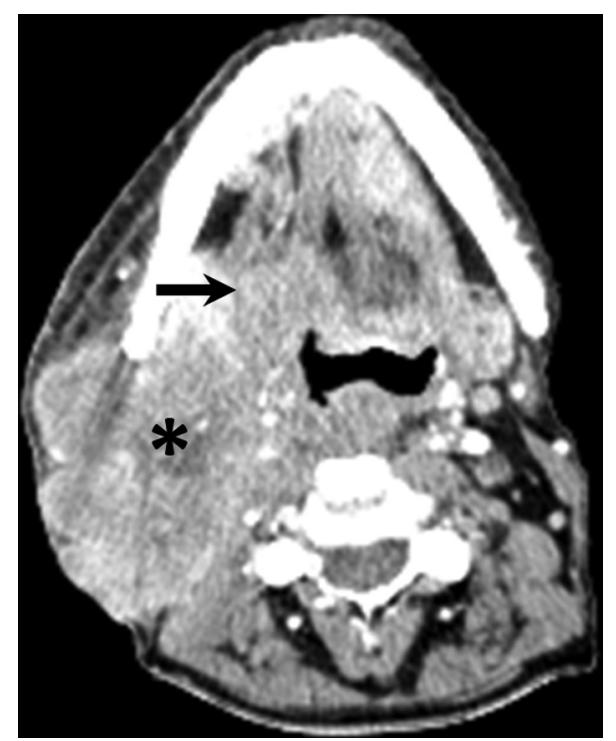

FIG 3. An example of radiographic extracapsular spread associated with a solid metastatic level II nodal mass (black asterisk) in a patient with right base of tongue oropharyngeal squamous cell carcinoma (black arrow).

confirmation or exclusion of recurrence when necessary for diagnosis.

\section{Primary End Points and Statistical Analysis}

Statistical analysis was performed by using SPSS statistics, Version 23 (IBM, Armonk, New York). Univariate Cox proportional hazard models were calculated to identify predictors of TF among the following variables: age (younger than 70 years versus 70 years and older), sex, T-stage, $\mathrm{N}$-stage, primary tumor location (tonsil or tongue base), rECS, tobacco use (ever or never used tobacco products), calendar year of treatment, and solid-versus-cystic lymph nodes. ${ }^{5}$ A multivariate Cox proportional hazard model was performed by using the same variables with a forward inclusion threshold of 0.1 . We used Pearson statistics to identify the correlation among variables that were included in the final Cox model. A $P$ value significance threshold of .05 was used for all clinical and demographic variables compared with solid/cystic nodal status. Most patients were men $(91.8 \%, 168 / 183)$, had a tonsil primary site $(56.2 \%, 103 / 183)$, presented with N2b disease $(53.0 \%, 97 / 183)$, and had a history of tobacco use $(68.9 \%$, $126 / 183)$. Solid and cystic patterns of nodal metastasis occurred in $42.6 \%(78 / 183)$ and $57.3 \%(105 / 183)$ of patients, respectively. The most frequent treatment technique was chemoradiotherapy $(72.1 \%, 132 / 183)$.

Average follow-up of all patients was 38.2 months (range, 1-104 months). In the disease-free group, median follow-up from initial diagnosis was 45 months (range, 1-104 months) with $10.6 \%(15 / 141)$ having $<24$ months' follow-up. TF occurred in 42 patients $(23.0 \% 42 / 183)$ at a mean of 14.6 months (range, $2-50$ months) following initial diagnosis. Among patients with rECS, $55.6 \%(10 / 18)$ experienced TF.

\section{Survival Analyses}

Univariate Cox proportional hazard models showed significant differences at $P<.05$ for the following variables: solid-versuscystic lymph nodes, $\mathrm{T}$-stage, $\mathrm{N}$-stage, and rECS. The multivariate Cox proportional hazard model resulted in a model that included solid-versus-cystic lymph nodes, T-stage, and rECS. A statistically significant correlation was found between rECS and solid-versuscystic nodes $(P=.03)$, but not between T-stage and solid-versuscystic nodes $(P=.66)$.

The Kaplan-Meier disease-free survival curves (Fig 5) demonstrate that overall disease-free survival was significantly lower among patients with solid metastatic regional lymph nodes at staging $(P=.013$; hazard ratio $=2.21 ; 95 \%$ confidence interval, 1.18-4.14). A univariate analysis of T-stages found a hazard ratio of 1.9 for T1 and T2 versus T3 and T4 $(P<$ $.001)$, and a univariate analysis of rECS found a hazard ratio of $3.3(P=.001)$.

Table 2 lists the locations of TF. The most common pattern of TF was distant metastases alone (19/42, 45.2\%). Most patients (90.4\%, 38/42) experienced TF within 24 months of the initial diagnosis. Four patients $(9.5 \%, 4 / 42)$ had $\mathrm{TF}>24$ months following completion of therapy.

AJNR Am J Neuroradiol 38:1405-10 Jul 2017 www.ajnr.org 


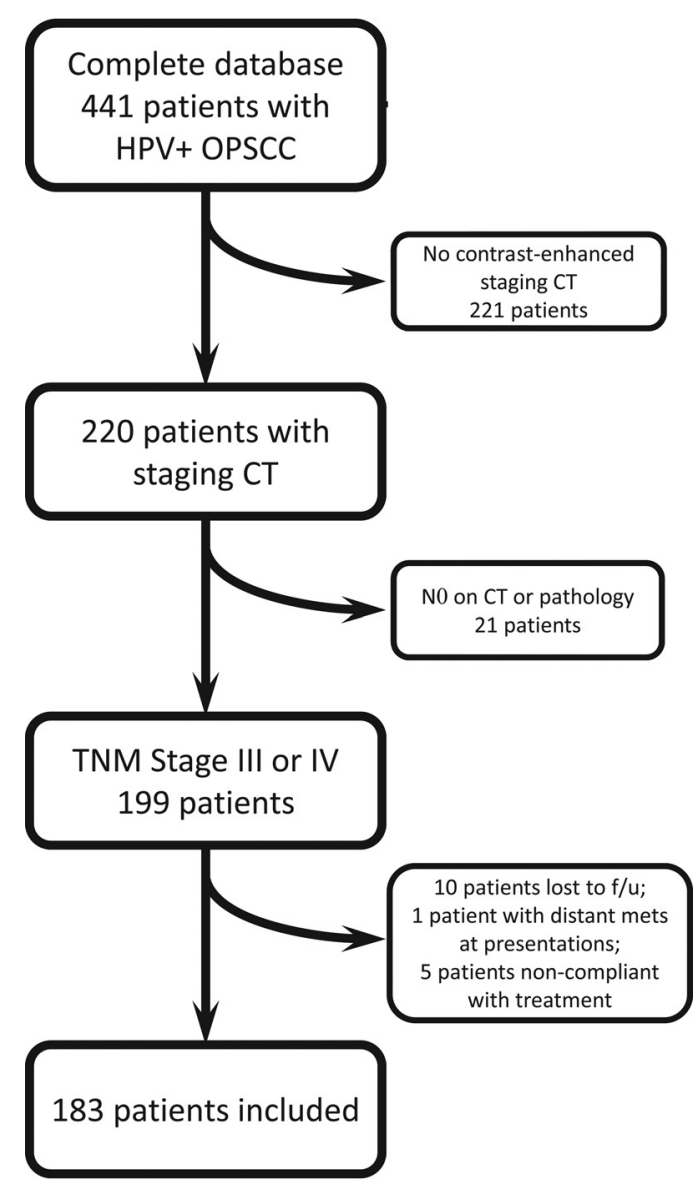

FIG 4. Data flow chart of patient selection.

\section{DISCUSSION}

In the era of rising HPV-related OPSCC affecting a population of young men, identifying reliable predictive imaging biomarkers is critical to developing tailored curative treatment regimens that minimize adverse effects. The goal of our study was to evaluate the prognostic value of the extent of cystic metastatic lymph node burden at staging for the prediction of TF in patients with stage III and IV (HPV)-related OPSCC. Our results suggest that the presence of solid lymph node metastases is an independent risk factor for TF in patients with HPV-associated OPSCC. Additionally, we found that T-stage and rECS remained independent predictors of TF in multivariate analysis. We hypothesize that greater overall solid nodal metastasis at staging more accurately reflects viable tumor burden, increasing the risk for locoregional failure and occult distant micrometastasis.

The prognostic utility of cystic-versus-solid metastatic lymph nodes in HPV-related OPSCC has not been previously reported, to our knowledge; however, the prognostic value of FDG PET/CT parameters in heterogeneous patient populations with OPSCC has been investigated. Alluri et $\mathrm{al}^{16}$ demonstrated that total metabolic tumor volume and primary metabolic tumor volume were associated with event-free survival in patients with stage III and IV HPV-related OPSCC. High standard uptake values of the primary tumor (standard uptake value $>8.0$ ) and of nodal metastasis (standard uptake value $>10.4$ ) have been associated with worse survival and greater rates of distant failure, respectively, in a heterogeneous population of patients with head and neck squamous
Table 1: Clinical and pathologic characteristics of patients ${ }^{a}$

\begin{tabular}{|c|c|c|c|}
\hline Characteristic & $\begin{array}{c}\text { All Patients } \\
(n=183) \\
(\text { No. })(\%)\end{array}$ & $\begin{array}{c}\text { Solid Node } \\
\text { Group } \\
(n=78) \\
\text { (No.) (\%) }\end{array}$ & $\begin{array}{c}\text { Cystic Node } \\
\text { Group } \\
(n=105) \\
(\text { No.) }(\%) \\
\end{array}$ \\
\hline Mean age (yr) & 56.1 & 56.2 & 56.1 \\
\hline Male sex & $168(91.8)$ & 75 (96.2) & $93(88.6)$ \\
\hline \multicolumn{4}{|l|}{ Smoking status } \\
\hline Never smoked (<1 Py) & $56(30.6)$ & $23(29.4)$ & $33(31.4)$ \\
\hline Ever smoked & $120(65.6)$ & $51(65.3)$ & $69(65.7)$ \\
\hline$<10 \mathrm{Py}$ & $14(7.7)$ & $4(5.1)$ & $10(9.5)$ \\
\hline$>10 \mathrm{Py}$ & $68(37.1)$ & $30(38.5)$ & $38(36.2)$ \\
\hline Unknown Py & $38(20.7)$ & $17(21.8)$ & $21(20.0)$ \\
\hline Unknown & $1(0.5)$ & $0(0.0)$ & $1(0.95)$ \\
\hline Other tobacco & $6(3.3)$ & $4(5.1)$ & $2(1.9)$ \\
\hline \multicolumn{4}{|l|}{ T classification } \\
\hline $\mathrm{Tl}$ & $74(40.4)$ & $28(35.9)$ & $46(43.8)$ \\
\hline $\mathrm{T} 2$ & 73 (39.9) & $35(44.9)$ & $38(36.2)$ \\
\hline T3 & $16(8.7)$ & $7(8.9)$ & $9(8.6)$ \\
\hline T4 & $17(9.3)$ & $7(9.0)$ & $10(9.5)$ \\
\hline Unknown & $3(1.6)$ & $1(1.3)$ & $2(1.9)$ \\
\hline \multicolumn{4}{|l|}{$\mathrm{N}$ classification } \\
\hline N1 & $31(16.9)$ & $13(16.7)$ & $18(17.1)$ \\
\hline $\mathrm{N} 2 \mathrm{a}$ & $24(13.1)$ & $11(14.1)^{\prime}$ & $13(12.4)$ \\
\hline $\mathrm{N} 2 \mathrm{~b}$ & $97(53.0)$ & $37(47.4)$ & $60(57.1)$ \\
\hline $\mathrm{N} 2 \mathrm{c}$ & $26(14.2)$ & 14 (17.9) & $12(11.4)$ \\
\hline N3 & $5(2.7)^{\prime}$ & $3(3.8)$ & $2(1.9)$ \\
\hline \multicolumn{4}{|l|}{ Overall stage } \\
\hline Stage III & $28(15.3)$ & 10 (12.8) & $18(17.1)$ \\
\hline Stage IV & 155 (84.7) & $68(87.2)$ & $87(82.9)$ \\
\hline \multicolumn{4}{|l|}{ Primary tumor site } \\
\hline Tonsil & $103(56.2)$ & $41(53.0)$ & $62(60.0)$ \\
\hline BOT & $76(41.5)$ & $35(44.9)$ & $41(39.0)$ \\
\hline Other & $2(1.1)$ & $1(1.3)$ & $1(0.95)$ \\
\hline Unknown & $2(1.1)$ & $1(1.3)$ & $1(0.95)$ \\
\hline \multicolumn{4}{|l|}{ Treatment } \\
\hline CRT & $132(72.1)$ & $57(73.1)$ & 75 (71.4) \\
\hline Operation & $12(6.6)$ & $5(6.4)$ & $7(6.7)$ \\
\hline Operation + MMT & $39(21.3)$ & $16(20.5)$ & $23(21.9)$ \\
\hline
\end{tabular}

Note:-Py indicates pack-year; BOT, base of tongue; CRT, chemoradiotherapy; MMT, multimodality therapy.

${ }^{a}$ No statistically significant correlation was found among any of the listed clinical and demographic variables compared with solid/cystic nodal status.

cell carcinoma. ${ }^{17}$ Cheng et al ${ }^{18}$ also determined that tumor total lesional glycolysis was an independent predictor of survival in patients with locally advanced OPSCC. The overall metastatic solid nodal metastasis volume on CT likely corresponds to FDGavid viable nodal metastasis on FDG PET/CT. Our results are congruent with FDG PET/CT studies suggesting that viable tumor volume at staging impacts prognosis. However, there is no clear consensus on whether primary tumor volume, nodal metastatic tumor volume, or total viable tumor (primary + nodes) volume has the greatest prognostic value.

The prognostic value of other imaging parameters has been evaluated. Davis et $\mathrm{al}^{19}$ found that lower nodal volume was associated with greater disease-free survival in patients with HPVrelated OPSCC, but did not distinguish solid-versus-cystic metastatic nodal volume. Spector et $\mathrm{al}^{9}$ reported that matted nodes, defined as " 3 nodes abutting one another with loss of intervening fat plane," are a novel imaging marker of poor prognosis in OPSCC, independent of HPV status. We did not evaluate matted nodes, given previously demonstrated poor interobserver agreement for this parameter. ${ }^{20}$ The negative predictive value of rECS 


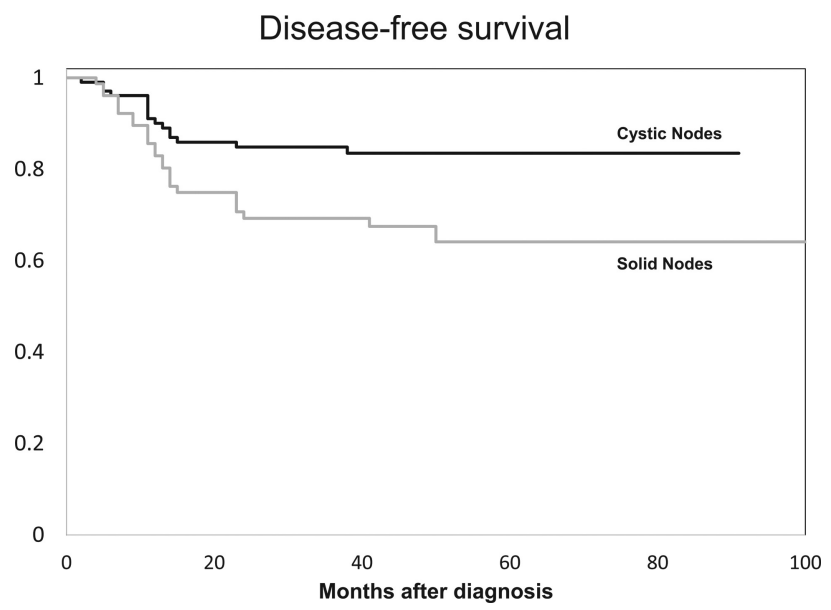

FIG 5. Kaplan-Meier survival curves. Overall disease-free survival was significantly lower among patients with cystic-versus-solid metastatic regional lymph nodes at staging $(P=.013$; hazard ratio $=2.21 ; 95 \%$ confidence interval, 1.18-4.14).

Table 2: Sites of treatment failure

\begin{tabular}{lc}
\hline \multicolumn{1}{c}{ Site $(\boldsymbol{n}=\mathbf{4 2})$} & No. (\%) \\
\hline Local & $3(7.1)$ \\
Regional & $7(16.7)$ \\
Distant & $19(45.2)$ \\
Local and regional & $6(14.3)$ \\
Local and distant & $1(2.4)$ \\
Regional and distant & $3(7.1)$ \\
Local, regional, and distant & $3(7.1)$ \\
\hline
\end{tabular}

on CT is poor; however, rECS on CT as evidenced by adjacent structure invasion has a good positive predictive value. ${ }^{20-23} \mathrm{We}$ found, in multivariate analysis, that rECS with invasion of surrounding soft tissues was an independent predictor of TF and that rECS correlated significantly with solid lymph node metastasis. Recently Liu et $\mathrm{al}^{24}$ did not find rECS to be an independent predictor of TF in a subset of patients with HPV-related OPSCC, though there was a trend toward worse survival in this group.

Kaka et $\mathrm{al}^{10}$ reported a predominance $(>80 \%)$ of central tumor necrosis, evidence of extracapsular spread, and clustering of nodes (analogous to matted nodes) in their case series of 8 aggressive HPV-related OPSCCs. Joo et $\mathrm{al}^{25}$ reported a significant positive correlation between lymph node size and high-risk HPV status and a significant positive correlation between lymph node size and cystic nodal metastases, yet with an overall better diseasespecific survival rate in HPV-related head and neck squamous cell carcinoma compared with HPV-negative tumors. Huang et $\mathrm{al}^{5}$ also found that N2a disease had better overall survival compared with N1 disease, applying traditional TNM staging in a cohort of patients with HPV-related OPSCC. The results of Joo et $\mathrm{al}^{25}$ and Huang et $\mathrm{al}^{5}$ support our hypothesis that solid or viable nodal metastatic burden may be prognostically more important, given the intranodal cystic changes frequently observed in HPV-related OPSCC.

We performed a multivariate analysis to address the possible covariance of radiologic and nonradiologic factors as prognosticators of TF. We could not confirm an association between TF and tobacco use, sex, or age, though an effect may exist but was too small to measure in the current study. Data on the impact of smoking on TF in the literature are conflicting. ${ }^{26-28}$ Our results are similar to those of O'Sullivan et al, ${ }^{28}$ who also found no effect of smoking on disease control in patients with HPV-related OPSCC, though overall survival among $>10$ pack-year smokers was reduced.

The results of the current study merit further investigation given the single-institution, retrospective nonrandomized nature of the study. We focused our study on HPV-related OPSCC and did not include non-HPV-related OPSCC, which constitutes an area of potential research. Due to the retrospective nature of this study, treatment regimens were variable, which can impact TF rates. Finally, we did not determine whether recurrences were treatable, and if treatable, whether treatment impacted overall survival.

\section{CONCLUSIONS}

Patients with HPV-related OPSCC who have solid lymph node metastases at staging CT have a higher risk for TF than patients with cystic lymph nodes. Larger scale, longer prospective studies are warranted to determine whether solid nodal metastasis is a useful imaging biomarker to risk-stratify patients for personalized treatment regimens in advanced-stage HPV-related OPSCC.

Disclosures: Srikala Narayanan-UNRELATED: Employment: work as an attending at Children's Hospital of University of Pittsburgh Medical Center; Other: This work was presented at the American Society of Neuroradiology conference and won outstanding oral presentation for head and neck in 2014; prize money was given by the American Society of Neuroradiology. Robert L. Ferris-UNRELATED: Board Membership: Astra-Zeneca/Medimmune, Bristol-Myers Squibb, Eli Lilly and Company, Merck, Pfizer; Grants/Grants Pending: Astra-Zeneca/Medlmmune, Bristol-Myers Squibb, Merck, VentiRx Pharmaceuticals*. *Money paid to the institution.

\section{REFERENCES}

1. Gillison ML, Koch WM, Capone RB, et al. Evidence for a causal association between human papillomavirus and a subset of head and neck cancers. J Natl Cancer Inst 2000;92:709-20 CrossRef Medline

2. Fakhry C, Westra WH, Li S, et al. Improved survival of patients with human papillomavirus-positive head and neck squamous cell carcinoma in a prospective clinical trial. J Natl Cancer Inst 2008;100: 261-69 CrossRef Medline

3. Ang KK, Harris J, Wheeler R, et al. Human papillomavirus and survival of patients with oropharyngeal cancer. N Engl J Med 2010;363: 24-35 CrossRef Medline

4. Mirghani H, Amen F, Blanchard P, et al. Treatment de-escalation in HPV-positive oropharyngeal carcinoma: ongoing trials, critical issues and perspectives. Int $J$ Cancer 2015;136:1494-503 CrossRef Medline

5. Huang SH, Xu W, Waldron J, et al. Refining American Joint Committee on Cancer/Union for International Cancer Control TNM stage and prognostic groups for human papillomavirus-related oropharyngeal carcinomas. J Clin Oncol 2015;33:836-45 CrossRef Medline

6. Horne ZD, Glaser SM, Vargo JA, et al. Confirmation of proposed human papillomavirus risk-adapted staging according to AJCC/ UICC TNM criteria for positive oropharyngeal carcinomas. Cancer 2016;122:2021-30 CrossRef Medline

7. Huang SH, Perez-Ordonez B, Liu FF, et al. Atypical clinical behavior of p16-confirmed HPV-related oropharyngeal squamous cell carcinoma treated with radical radiotherapy. Int J Radiat Oncol Biol Phys 2012;82:276-83 CrossRef Medline

8. O'Sullivan B, Huang SH, Perez-Ordonez B, et al. Outcomes of HPVrelated oropharyngeal cancer patients treated by radiotherapy

AJNR Am J Neuroradiol 38:1405-10 Jul 2017 www.ajnr.org

1409 
alone using altered fractionation. Radiother Oncol 2012;103:49-56 CrossRef Medline

9. Spector ME, Gallagher KK, Light E, et al; University of Michigan Head Neck Specialized Program of Research Excellence (SPORE) Program. Matted nodes: poor prognostic marker in oropharyngeal squamous cell carcinoma independent of HPV and EGFR status. Head Neck 2012;34:1727-33 CrossRef Medline

10. Kaka AS, Kumar B, Kumar P, et al. Highly aggressive human papillomavirus-related oropharyngeal cancer: clinical, radiologic, and pathologic characteristics. Oral Surg Oral Med Oral Pathol Oral Radiol 2013;116:327-35 CrossRef Medline

11. Goldenberg D, Begum S, Westra WH, et al. Cystic lymph node metastasis in patients with head and neck cancer: an HPV-associated phenomenon. Head Neck 2008;30:898-903 CrossRef Medline

12. Morani AC, Eisbruch A, Carey TE, et al. Intranodal cystic changes: a potential radiologic signature/biomarker to assess the human papillomavirus status of cases with oropharyngeal malignancies. J Comput Assist Tomogr 2013;37:343-45 CrossRef Medline

13. Chiosea SI, Grandis JR, Lui VW, et al. PIK3CA, HRAS and PTEN in human papillomavirus positive oropharyngeal squamous cell carcinoma. BMC Cancer 2013;13:602 CrossRef Medline

14. Maxwell JH, Ferris RL, Gooding W, et al. Extracapsular spread in head and neck carcinoma: impact of site and human papillomavirus status. Cancer 2013;119:3302-08 CrossRef Medline

15. Edge SB, Byrd DR, Compton CC, et al, eds. AJCC Cancer Staging Manual. 7th ed. New York: Springer; 2010:41-56

16. Alluri KC, Tahari AK, Wahl RL, etal. Prognostic value of FDG PET metabolic tumor volume in human papillomavirus-positive stage III and IV oropharyngeal squamous cell carcinoma. AJR Am J Roentgenol 2014;203:897-903 CrossRef Medline

17. Kubicek GJ, Champ C, Fogh S, et al. FDG-PET staging and importance of lymph node SUV in head and neck cancer. Head Neck Oncol 2010;2:19 CrossRef Medline

18. Cheng NM, Chang JT, Huang CG, et al. Prognostic value of pretreatment ${ }^{18} \mathrm{~F}$-FDG PET/CT and human papillomavirus type 16 testing in locally advanced oropharyngeal squamous cell carcinoma. Eur J Nucl Med Mol Imaging 2012;39:1673-84 CrossRef Medline

19. Davis KS, Lim CM, Clump DA, et al. Tumor volume as a predictor of survival in human papillomavirus-positive oropharyngeal cancer. Head Neck 2016;38(suppl 1):E1613-17 CrossRef Medline

20. Chai RL, Rath TJ, Johnson JT, et al. Accuracy of computed tomography in the prediction of extracapsular spread of lymph node metastases in squamous cell carcinoma of the head and neck. JAMA Otolaryngol Head Neck Surg 2013;139:1187-94 CrossRef Medline

21. Branstetter BF, Rath TJ, Kubicek GJ. Accuracy of computed tomography for predicting pathologic nodal extracapsular extension in patients with head and neck cancer undergoing initial surgical resection: in regard to Prabhu, et al. Int J Radiat Oncol Biol Phys 2014;89:434-35 CrossRef Medline

22. Prabhu RS, Magliocca KR, Hanasoge S, et al. Accuracy of computed tomography for predicting pathologic nodal extracapsular extension in patients with head-and-neck cancer undergoing initial surgical resection. Int J Radiat Oncol Biol Phys 2014;88:122-29 CrossRef Medline

23. Maxwell JH, Rath TJ, Byrd JK, et al. Accuracy of computed tomography to predict extracapsular spread in p16-positive squamous cell carcinoma. Laryngoscope 2015;125:1613-18 CrossRef Medline

24. Liu JT, Kann BH, De B, et al. Prognostic value of radiographic extracapsular extension in locally advanced head and neck squamous cell cancers. Oral Oncol 2016;52:52-57 CrossRef Medline

25. Joo YH, Cho KJ, Park JO, et al. High-risk human papillomavirus and lymph node size in patients with single node metastasis of oral and oropharyngeal cancer. Acta Otolaryngol 2014;134:395-400 CrossRef Medline

26. Maxwell JH, Kumar B, Feng FY, et al. Tobacco use in human papillomavirus-positive advanced oropharynx cancer patients related to increased risk of distant metastases and tumor recurrence. Clin Cancer Res 2010;16:1226-35 CrossRef Medline

27. Gillison ML, Zhang Q, Jordan R, et al. Tobacco smoking and increased risk of death and progression for patients with p16-positive and p16-negative oropharyngeal cancer. J Clin Oncol 2012;30: 2102-11 CrossRef Medline

28. O'Sullivan B, Huang SH, Siu LL, et al. Deintensification candidate subgroups in human papillomavirus-related oropharyngeal cancer according to minimal risk of distant metastasis. J Clin Oncol 2013; 31:543-50 CrossRef Medline 